\title{
The Analysis of Risk Factors to Hypotension Occurring after Caesarean Spinal Anesthesia for Parturients with Scarred Uterus
}

\section{Wei Chen ( $\mathbf{D}$ 874277327@qq.com )}

The First Hospital of Wannan Medical College https://orcid.org/0000-0003-4562-8363

\section{Ya Cao}

The First Affiliated Hospital Of Wannan Medical College

\section{Quan Yong Chen}

The First Affiliated Hospital Of Wannan Medical College

Yan Lu

The First Affiliated Hospital Of Wannan Medical College

\section{Bing Wang}

The First Affiliated Hospital Of Wannan Medical College

\section{Hai Wang}

The First Affiliated Hospital Of Wannan Medical College

\section{Fang Ding}

The First Affiliated Hospital Of Wannan Medical College

\section{Ling Guo}

The First Affiliated Hospital Of Wannan Medical College

\section{Research article}

Keywords: Hypotension, Spinal anesthesia, Cesarean section, Risk Factors

Posted Date: August 20th, 2020

DOI: https://doi.org/10.21203/rs.3.rs-19160/v3

License: (1) This work is licensed under a Creative Commons Attribution 4.0 International License. Read Full License 


\section{Abstract}

Background囚This study examined the risk factors for hypotension after caesarean spinal anesthesia with low dose of bupivacaine and sulfentanyl in parturients with scarred uterus.

Methods $\ A$ total of 322 singleton-pregnancy parturients with scarred uterus who had been scheduled for caesarean spinal anesthesia were randomly sampled. The data on the basic information of the parturients, the gestation, the fetus and the anesthesia were recorded and filed according to the clinical questionnaires on hypotension in caesarean section. The parturients whose systolic blood pressure dropped below $90 \mathrm{mmHg}$ or decreased by $20 \%$ during the time from the completion of anesthesia until the delivery of infant were classified as Group hypotension (Group H) and the rest were in Group nonhypotension (Group N). This study analyzed the correlation of 39 factors to the occurrence of hypotension, and further analyzed the statistically significant factors through binary classification logistic regression.

Results $₫$ Of the 322 sampled parturients, 148 parturients suffered hypotension. The incidence of hypotension in this study was $45.96 \%$. The result of univariate analysis showed statistically significant differences in the factors including height $(p=0.005)$, post-pregnancy Body Mass Index (BMI) $(p=0.00)$, fasting time $(p=0.031)$, weight gain in gestation $(p=0.000)$, fundal height $(p=0.047)$, exercise history in gestation $(p=0.006)$ and dermatomal level of analgesia $(p=0.000)$ between the two groups. The variables with statistical significance were analyzed by multivariate logistic regression model. The result showed that $\mathrm{BMI}$ in gestation $(\mathrm{OR}=1.146,95 \% \mathrm{Cl} 1.041-1.262, p<0.05)$, weight gain in gestation $(\mathrm{OR}=1.126,95 \%$ $\mathrm{Cl} 1.060-1.198, p<0.001)$, exercise history in gestation ( $\mathrm{OR}=0.399,95 \% \mathrm{Cl} 0.205-0.778, p=0.007)$, and dermatomal level of analgesia $(\mathrm{OR}=2.248,95 \% \mathrm{Cl} 1.645-3.074, p<0.001)$ were risk factors for hypotension after caesarean spinal anesthesia in parturients with scarred uterus.

Conclusion区The incidence of hypotension after caesarean spinal anesthesia in parturients with scarred uterus was relatively high. The post-pregnancy BMl, weight gain in gestation, exercise history in gestation and dermatomal level of analgesia after anesthesia were risk factors for hypotension after caesarean spinal anesthesia in parturients with scarred uterus. These findings play an important role in predicting the occurrence of hypotension after caesarean spinal anesthesia in parturients with scarred uterus.

Trial registration冈Chinese Clinical Trial Registry (chiCTR-ROC-17011251)

\section{Background}

Spinal anesthesia has been increasingly universally selected for caesarean section, and one of the commonly seen complications is hypotension. The incidence of hypotension in parturients is much higher than in non-gestational women. The incidence of hypotension after spinal anesthesia in caesarean section can reach $20-100 \%{ }^{(1-3)}$. Hypotension can cause nausea, vomiting, or even maternal consciousness loss and respiratory depression, increasing the risk of aspiration. Severe hypotension lowers uteroplacental blood flow, leading to fetal acidosis, and further damages the central nervous 
system and puts the fetus in life risk ${ }^{(4-5)}$. These are the major complications and challenges faced by parturients when spinal anesthesia is used in caesarean section. Previous study found that factors including age ( $₫ 35$ years old), obesity, higher blockade, over-sized fetus and twin fetus are critical factors causing hypotension after spinal anesthesia in parturients ${ }^{(6)}$. Some studies indicated that the incidence of hypotension in parturients increases with multiple caesarean sections ${ }^{(7)}$. Therefore, this study sampled the parturients with scarred uterus due to multiple caesarean sections in order to investigate the risk factors related to the mother, the fetus, and anesthesia. This study aimed to provide a theoretical basis for prevention of hypotension in this group of patients in the clinic.

\section{Method}

In this study, all the participants were singleton-pregnancy parturients with scarred uterus. The parturients with high-risk pregnancy, twins, congenital malformation fetus and fetal distress were excluded. The participants were recruited from January to December 2019 from the Yijishan Hospital of Wannan Medical College. The following information about the parturients was collected before spinal anesthesia: age, height, pre-pregnancy weight, pre-pregnancy BMI, post-pregnancy weight, post-pregnancy BMI, weight gain in gestation, days of pregnancy, fasting time, smoking history, anxiety history, exercise history in gestation, hypertension history, diabetes history, hypothyroidism history, premature rupture of membrane, preferred sleeping posture in gestation, the volume of preoperative fluid infusion, basal heart rate, basal blood pressure, fundal height, abdominal circumference, fetal ultrasound data (including fetal biparietal diameter (BPD), fetal femur length (FL), amniotic fluid index, maximum vertical pocket depth, hepatic dysfunction, anemia in gestation $(\mathrm{Hb}<110 \mathrm{~g} / \mathrm{L}$, $\mathrm{Hct}<0.33 \%)$, hypoproteinemia (total protein tested in laboratory in gestation $<60 \mathrm{~g} / \mathrm{L}$ or albumin $<35 \mathrm{~g} / \mathrm{L}$ ), and electrolyte disturbances (serum potassium $<3.5 \mathrm{mmol} / \mathrm{L}$, serum calcium $<2.2 \mathrm{mmol} / \mathrm{L}$ ). Heart rate and blood pressure were consecutively measured three times every two minutes when the parturient laid on the operation table, and the mean value was the basal systolic blood pressure and the basal heart rate. To measure the fundal height and abdominal circumference, the parturients laid in supine position on the operation table after urination. The height from the symphysis pubis to the uterine fundus measured by soft ruler is the fundal height. The perimeter of the waist and abdomen at the level of umbilicus is the abdominal circumference.

The temperature of the operating room was maintained between $22^{\circ} \mathrm{C}$ and $24^{\circ} \mathrm{C}$, and the relative humidity was between $50 \%$ and $60 \%$. Parturients were in supine position. When the parturients' breathing stabilized, they were supplied with oxygen mask for oxygen inhalation at $3 \mathrm{~L} / \mathrm{min}$, and the heart rate, blood pressure and oxygen saturation were monitored. When the vein was ready, the parturients were given intravenous infusion. An anesthetist with extensive clinical experience administered the subarachnoid block, and parturients were punctured in the place between L3 and L4 in left-recumbent position. After successful puncture, parturients received $9 \mathrm{mg}$ bupivacaine and $2.5 \mu \mathrm{g}$ sulfentanyl. The anesthetic injection time was recorded. After anesthesia, the parturients were tilted $15^{\circ}$ leftward. The blood pressure and heart rate were measured every two minutes. From the completion of anesthesia to the delivery of fetus with umbilical cord cut off, a drop of $20 \%$ SBP from baseline or lower than $90 \mathrm{mmHg}$ 
was defined as hypotension. In case of hypotension, the anesthesiologist administered 5-10 mg ephedrine if the maternal heart rate is slow or $50-100 \mu \mathrm{g}$ phenylephrine if the maternal heart rate is fast. The dosage of vasoactive agent used in the operation was recorded. After 10 minutes, the dermatomal level of analgesia was measured with alcohol test method and the highest level of analgesia was recorded. After delivery, the fetal position, the gender and the weight of the newborn were recorded.

\section{Statistical analysis}

Statistical analysis was performed with the SPSS 22.0. The dichotomous variable hypotension after spinal anesthesia (yes/no) was used as the target criterion.

First, univariate analysis was used to analyze the correlation of variables with hypotension, and then the mean value and standard deviation were calculated. Thereafter, chi-square test or Fisher's exact test was adopted to analyze the correlation of categorical variables with hypotension. A $p<0.05$ indicated statistically significant difference.

Second, statistically significant factors were analyzed with univariate analysis. In the analysis, independent variables were selected through stepwise selection function in logistic regression model. The boundary-value $(a \leq 0.05)$ and the elimination-value $(a \geq 0.10)$ of the selected variables were determined. The independent risk factors correlated to hypotension after spinal anesthesia in parturients with scarred uterus were screened. The odds ratio (OR) and the calculation difference at $95 \%$ confidence interval $(\mathrm{Cl})$ were compared. A $p<0.05$ indicated statistically significant difference.

\section{Results}

A total of 322 parturients were sampled in this study. According to the definition of hypotension, the parturients were divided into two groups, Group Hypotension (Group H) and Group Non-hypotension (Group N). Of the 322 parturients, 148 parturients suffered hypotension. The incidence was $45.96 \%$.

1. Among the variables related to maternal basic information, height $(p=0.045)$, fasting time $(p=$ $0.031)$,and exercise history in gestation ( $p=0.006)$ were correlated with high incidence of hypotension after spinal anesthesia in parturients with scarred uterus (Table 1).

Table 1. The variables related to the basic information of parturients (c2 test or Fisher's exact test)

Group H Group N p-value 


\begin{tabular}{|c|c|c|c|}
\hline Age (years) & & & 0.93 \\
\hline$\leq 35$ & 98 & 116 & \\
\hline$\square 35$ & 50 & 58 & \\
\hline Height & $158.96 \pm 4.31$ & $160.37 \pm 4.55$ & $0.005^{* *}$ \\
\hline Pre-pregnancy Weight (kg) & $55.73 \pm 7.60$ & $56.66 \pm 8.40$ & 0.30 \\
\hline \multicolumn{4}{|l|}{ Pre-pregnancy BMI (kg/m2) } \\
\hline Fasting time $(\mathrm{h})$ & $22.05 \pm 2.87$ & $21.99 \pm 2.81$ & 0.85 \\
\hline \multicolumn{4}{|l|}{ Sickness history } \\
\hline Yes & $11.94 \pm 3.25$ & $11.08 \pm 3.90$ & $0.031 *$ \\
\hline No & & & 0.69 \\
\hline Smoking history & 28 & 36 & \\
\hline Yes & 120 & 138 & \\
\hline No & & & 0.41 \\
\hline Anxiety history & 2 & 0 & \\
\hline Yes & 146 & 174 & \\
\hline No & & & 0.61 \\
\hline Exercise history & 18 & 18 & \\
\hline Yes & 130 & 156 & \\
\hline No & & & $0.006^{* *}$ \\
\hline Hypertension & 34 & 20 & \\
\hline Yes & 114 & 154 & \\
\hline No & & & 0.17 \\
\hline Diabetes & 10 & 6 & \\
\hline Yes & 138 & 168 & \\
\hline No & & & 0.36 \\
\hline Hypothyroidism & 29 & 30 & \\
\hline Yes & 128 & 144 & \\
\hline No & & & 0.39 \\
\hline Single child & 8 & 6 & \\
\hline Yes & 140 & 168 & \\
\hline No & & & 0.12 \\
\hline Liver Function & 24 & 18 & \\
\hline Yes & 124 & 156 & \\
\hline No & & & 0.37 \\
\hline
\end{tabular}




\begin{tabular}{llll} 
Anemia & 6 & 4 & \\
Yes & 142 & 170 & 0.14 \\
No & & & \\
Hypoproteinemia & 56 & 8 & 0.85 \\
Yes & 92 & 94 & \\
No & & & \\
Electrolyte disturbances & 132 & 154 & 0.91 \\
Yes & 16 & 20 & \\
No & & & \\
& & & \\
& 6 & 172 & \\
\hline
\end{tabular}

Note: $p \llbracket 0.05$ indicates that the difference is statistically significant. Pre-pregnancy weight $=$ the weight before pregnancy.*p $\llbracket 0.05$ vs. Group N; ${ }^{* *} p<0.01$ vs. Group N.

Among the variables related to gestation, post-pregnancy BMI $(p=0.000)$, fundal height $(p=0.047)$, and weight gain in gestation $(p=0.000)$ were related to high incidence of hypotension after spinal anesthesia in parturients with scarred uterus (Table 2).

Table 2. The variables related to gestation (c2 test or Fisher's exact test) 


\begin{tabular}{|c|c|c|c|}
\hline \multirow[b]{2}{*}{ Post-pregnancy weight (kg) } & \multicolumn{2}{|c|}{ Group H Group N } & \multirow{2}{*}{$\begin{array}{l}p \text {-value } \\
0.08\end{array}$} \\
\hline & $71.57 \pm 8.18$ & $69.94 \pm 8.44$ & \\
\hline \multicolumn{4}{|l|}{ Post-pregnancy BMI (kg/m2) } \\
\hline Weight gain in gestation (kg) & $28.31 \pm 2.99$ & $27.15 \pm 2.68$ & $0.00 * *$ \\
\hline \multicolumn{4}{|l|}{ Fundal height (cm) } \\
\hline Abdominal circumference (cm) & $15.85 \pm 4.11$ & $13.28 \pm 4.51$ & $0.00 * *$ \\
\hline \multicolumn{4}{|l|}{ Gestational age (week) } \\
\hline$\square 37$ & $33.96 \pm 2.79$ & $33.76 \pm 2.53$ & $0.047 *$ \\
\hline$\geq 37$ & $101.42 \pm 5.22$ & $101.17 \pm 6.48$ & 0.71 \\
\hline \multicolumn{4}{|l|}{ Amniotic fluid index } \\
\hline Maximum vertical pocket depth (cm) & & & 0.94 \\
\hline Premature rupture of membrane & 14 & 16 & \\
\hline Yes & 134 & 158 & \\
\hline No & $51.50 \pm 19.26$ & $54.48 \pm 22.10$ & 0.20 \\
\hline Fetal position & $119.22 \pm 42.30$ & $112.67 \pm 41.15$ & 0.16 \\
\hline \multicolumn{4}{|l|}{$\mathrm{L}$} \\
\hline $\mathrm{R}$ & & & 0.11 \\
\hline \multicolumn{4}{|l|}{ Preferred sleeping posture in gestation } \\
\hline L1 & 8 & 18 & \\
\hline $\mathrm{R} 1$ & 140 & 156 & \\
\hline $\mathrm{S}$ & & & 0.66 \\
\hline \multirow[t]{7}{*}{ No } & 138 & 160 & \\
\hline & 10 & 14 & \\
\hline & & & 0.086 \\
\hline & 60 & 64 & \\
\hline & 12 & 22 & \\
\hline & 22 & 40 & \\
\hline & 54 & 48 & \\
\hline
\end{tabular}


Note: Post-pregnancy BMI = the weight of parturient in caesarean section; $L=$ fetal position is on the left side of pelvis; $\mathrm{R}=$ fetal position is on the right side of pelvis; $\mathrm{L} 1$ = sleeping on left side is preferred during gestation; $\mathrm{S}$ $=$ sleeping on back is preferred during gestation; * $p \llbracket 0.05$ vs. Group N; ${ }^{* *} p<0.01$ vs. Group N. Among the variables related to fetus, biparietal diameter (BPD), femur length (FL), neonatal weight and gender were not significantly related to the incidence of hypotension after spinal anesthesia in parturients with scarred uterus (Table 3).

Table 3. Variables related to fetus (c2 test or Fisher's exact test)

\begin{tabular}{llll}
\hline & Group H & Group N & $p$-value \\
\hline BPD (cm) & $92.96 \pm 4.16$ & $93.38 \pm 3.67$ & 0.34 \\
FL (cm) & $72.53 \pm 3.77$ & $73.14 \pm 3.27$ & 0.12 \\
Neonatal weight (g) & & & 0.36 \\
$\square 2500$ & 16 & 12 & \\
$2500-4000$ & 122 & 146 & \\
$\square 4000$ & 10 & 16 & 0.32 \\
Fetal gender & & & \\
Male & 78 & 82 & \\
Female & 70 & 92 & \\
& & & \\
\hline
\end{tabular}

Note: $\mathrm{BPD}=$ fetal biparietal diameter; $\mathrm{FL}=$ fetal femur length; ${ }^{*} p \llbracket 0.05$ vs. Group N; ${ }^{* *} p<0.01$ vs. Group N. Among the variables related to anesthesia, dermatomal level of analgesia was the only one factor related to high incidence of hypotension after spinal anesthesia in parturients with scarred uterus (Table 4).

Table 4. Variables related to anesthesia cFisher's exact test) 


\begin{tabular}{|c|c|c|c|}
\hline & Group $\mathrm{H}$ & Group N & $p$-value \\
\hline Volume of fluid infusion (ml) & & & 0.94 \\
\hline \multicolumn{4}{|l|}{$\square 500$} \\
\hline$\geq 500$ & 134 & 158 & \\
\hline Blood pressure before anesthesia ( $\mathrm{mmHg}$ ) & 14 & 16 & \\
\hline$\square 120$ & & & 0.23 \\
\hline \multicolumn{4}{|l|}{$\geq 120$} \\
\hline Heart rate before anesthesia (bpm) & 66 & 66 & \\
\hline$\leq 100$ & 82 & 108 & \\
\hline$\square 100$ & & & 0.62 \\
\hline \multicolumn{4}{|l|}{ Dermatomal level of analgesia } \\
\hline T10 & 100 & 122 & \\
\hline T8 & 48 & 52 & \\
\hline T6 & & & $0.00 * *$ \\
\hline \multicolumn{4}{|l|}{$\mathrm{T} 4$} \\
\hline The time of anesthetic injection (s) & 12 & 34 & \\
\hline$\leq 15$ & 58 & 86 & \\
\hline \multirow[t]{5}{*}{$\square 15$} & 52 & 48 & \\
\hline & 26 & 6 & \\
\hline & & & 0.84 \\
\hline & 130 & 144 & \\
\hline & 22 & 26 & \\
\hline
\end{tabular}

Note: ${ }^{* *} p<0.01$ vs. Group N. 
2. The statistically significant variables were analyzed by multivariate logistic regression. Among the variables analyzed, the weight gain in gestation (OR 1.127, 95\% Cl: 1.06-1.198), post-pregnancy BMI (OR $1.146,95 \% \mathrm{Cl}: 1.041-1.262$ ), exercise history in gestation (OR $0.399,95 \% \mathrm{Cl}: 0.205-0.778$ ) and the dermatomal level of analgesia (OR 2.248, 95\% Cl: 1.645-3.074) were independent risk factors for the occurrence of hypotension after spinal anesthesia in parturients with scarred uterus. Due to the lack of significant correlations shown in the model, all other indicators were excluded from the logistic regression model (Table 5).

Table 5. Analysis of risk factors by multivariate logistic regression

\begin{tabular}{llllll}
\hline Variables & $B$ & $\mathrm{SE}$ & $p$-value & OR & \multicolumn{1}{l}{$C I$} \\
\hline Weight gain in gestation & 0.119 & 0.049 & $0.000^{* *}$ & 1.127 & $1.060-1.198$ \\
Post-pregnancy BMI & & & & & \\
Exercise history & 0.136 & 0.049 & $0.005^{* *}$ & 1.146 & $1.041-1.262$ \\
Dermatomal levels of analgesia & $-0.91-$ & 0.341 & $0.007^{* *}$ & 0.399 & $0.205-0.778$ \\
Constant & 0.810 & 0.16 & $0.00^{* *}$ & 2.248 & $1.645-3.074$ \\
& & & & & \\
& -6.82 & 1.46 & 0.000 & & \\
& & & & & \\
& & & & & \\
\end{tabular}

Note: SE: standard error, CI: 95\% confidence interval; OR: Odds-ratio

\section{Discussion}

So far, most studies have indicated that reducing the dose of local anesthetic in spinal anesthesia can effectively decrease the incidence of hypotension in parturients. In Van de Velde's study, the parturients in the high-dose group were injected with $9.5 \mathrm{mg}$ bupivacaine into the subarachnoid cavity, while the dosage of bupivacaine in the low-dose group was reduced to $6.5 \mathrm{mg}$. Additionally, $2.5 \mu \mathrm{g}$ sulfentanyl was added in both groups. The result showed that the mean minimum systolic blood pressure (SBP) in the low-dose group was apparently higher than in the high-dose group, and the incidence of hypotension in the lowdose group was distinctly lower than in the high-dose group. Due to the use of opioid analgesic, all parturients achieved satisfactory anesthetic effect.However,they used a CSE technique and could give epidural top-ups if required or they could anticipate pain if surgery was unexpectedly prolonged ${ }^{(8)}$. Farzi analyzed the analgesia duration and spinal anesthesia complications due to the use of bupivacaine with fentanyl or sulfentanyl, and placebo. The result showed that the use of bupivacaine with $25 \mu \mathrm{g}$ fentanyl or $2.5 \mu \mathrm{g}$ sulfentanyl as intrathecal drug can increase the analgesia duration and hemodynamic stability, 
without causing serious complications. Therefore, this study adopted low dose of bupivacaine (9 mg) and sulfentanyl $(2.5 \mu \mathrm{g})$ as the intrathecal drug ${ }^{(9)}$, which not only reduced the incidence of hypotension but also ensured better analgesia effect.

According to statistics, the increase in caesarean section rates in Northern Europe is due to the increase in the caesarean delivery rate (CDR) of primiparas and the growing proportion of parturients with caesarean history ${ }^{(10)}$. The uterus of a parturient with caesarean section history is already scarred, so caesarean section is the most likely choice for any subsequent delivery. The operation of parturient with scarred uterus is tough and complicated, and the difficulty of anesthesia is increased. Re-caesarean section obviously puts the parturient and fetus at higher risk. One of the essential factors for operation success is anesthesia. At present, single-shot spinal anesthesia can be safely used in re-caesarean parturients. Nonetheless, due to several physiological changes occurring in the expectant mothers, hypotension remains the most common complication in re-caesarean parturients ${ }^{(11)}$.

In this study, the incidence of hypotension after spinal anesthesia in parturients with scarred uterus was 45.96\%. The factors including height, post-pregnancy BMI, weight gain in gestation, fasting time, exercise in gestation and dermatomal level of analgesia were statistically related to hypotension after spinal anesthesia in caesarean section. Moreover, $\mathrm{BMI}(O R=1.146)$, weight gain in gestation $(O R=1.127)$, exercise in gestation $(O R=0.399)$, and dermatomal level of analgesia $(O R=2.248)$ were predictors of hypotension after spinal anesthesia in caesarean section. Ohpasanon and Bernd ${ }^{(12)}$ found that age, prepregnancy BMI and weight gain during pregnancy were risk factors for hypotension in primiparas after spinal anesthesia. In this study, pregnant women with scarred uterus were selected as the research subjects. Different from primiparas, BMl after pregnancy was one of the strongest predictors of hypotension in women with scarred uterus after spinal anesthesia. Meanwhile, this study also included exercise during pregnancy as a factor, which was not examined in previous studies.

The high incidence of hypotension is relatively contributed by physiological changes during gestation. This study found that four independent variables were closely related to the high incidence of hypotension after caesarean spinal anesthesia.

Consistent with previous studies ${ }^{(12)}$, this study confirmed that the increase of post-pregnancy BMI is a risk factor for hypotension triggered by spinal anesthesia in caesarean section. Pitkanen et al. indicated that the diffusion of bupivacaine of equal dose is closely correlated to post-pregnancy BMI(13-14). The increase of intra-abdominal pressure caused by cyesis or obesity can reduce the volume of cerebrospinal fluid and increase dermatomal level of analgesia. Therefore, the dose of local anesthetic to be injected into the subarachnoid cavity of parturients at full-term is one-third less than that of non-pregnant patients. Meanwhile, larger rump of obese patient may result in higher inclination of lumbar and thoracic vertebrae, and further accelerate the diffusion of local anesthetic from subarachnoid cavity to head. Under the combined effect of the two factors, the use of equal dose of local anesthetic probably leads to over-blockade and results in higher incidence of hypotension. 
Kitahara ${ }^{(15)}$ believed that in supine position, the local anesthetic is concentrated in the lowest part of thoracic vertebrae, regardless of the height of patients. However, Greene ${ }^{(16)}$ believed that because taller patients have larger space in subarachnoid cavity and larger volume of cerebrospinal fluid, the local anesthetic should reach lower dermatomal level of analgesia within the same distance from the injection site. In addition, cerebrospinal fluid can dilute the injection. The larger the volume of cerebrospinal fluid, the more diluted the injected drug will be. Hence, both factors limit the diffusion of local anesthetic in taller patients, which is consistent with the result of this study. This study found that taller parturients have lower risk of hypotension after spinal anesthesia in caesarean section. However, according to the result of multivariate logistic regression model, this variable was not significantly related to the incidence of hypotension after spinal anesthesia in caesarean section.

This study found that the risk of hypotension increases with the increase in weight gain during gestation. In contrast, a previous study found that weight gain $<11 \mathrm{~kg}$ during gestation is a risk factor for hypotension triggered by spinal anesthesia ${ }^{(17)}$. Meanwhile, another study found that weight gain $>11 \mathrm{~kg}$ during gestation is a risk factor for hypotension after spinal anesthesia ${ }^{(18)}$.

Normally, parturients are required to fast for caesarean section. Long-time fasting probably results in insufficient capacity, relative dehydration and leads to higher risk of hypotension. This study found that over-fasting was one of the risk factors leading to hypotension after spinal anesthesia. However, in the multivariate logistic regression, this variate was not significantly related to the incidence of hypotension after spinal anesthesia in caesarean section.

Buchheit et al. showed that exercise can intensify the overall heart rate variability and promote the activity of cardiac sympathetic nerve and parasympathetic nerve, facilitating the transmission from sympathetic-parasympathetic nerve balance to parasympathetic-enhanced nerve activity ${ }^{(19)}$. This study revealed that the change of sympathetic nerve activity might be related to the reduction of hypotension incidence after spinal anesthesia in parturients with exercise history.

Intrathecal block usually causes varying degrees of blood pressure decline with heart rate slowing. These effects are proportional to the level and degree of dermatomal analgesia. Vessel tension is determined by arterial and venous smooth muscles controlled by sympathetic fibers in T5-L1. Blocking the nerves might cause venous capacitance expansion, vessel vasodilation, hypostasis, and venous return decrease. Arterial vasodilation can even reduce systemic vascular resistance. When dermatomal level of analgesia exceeds T4, cardioacceleration fibers become blocked, resulting in heart rate decline and cardiac output decrease. Arteriectasis and venectasia combined with bradycardia might cause severe hypotension. Arterial vasodilation might be affected by compensatory vasoconstriction above blockade, especially when the dermatomal analgesia is limited to the lower thoracic segment. The result of this study is consistent with previous study ${ }^{(20)}$. Higher dermatomal level of analgesia results in higher risk of hypotension in parturients after anesthesia. 
Chung ${ }^{(21)}$ et al. evaluated the correlation of fundal height with dermatomal level of analgesia, and found no clear correlation between them. However, another study revealed that for parturients with higher fundal height and higher intra-abdominal pressure, the diffusion of local anesthetic in the subarachnoid cavity was accelerated in early stage, resulting in higher dermatomal level of analgesia ${ }^{(18)}$. Univariate analysis showed that fundal height was significantly related to the incidence of hypotension after caesarean spinal anesthesia in this study. However, multivariate logistical regression model showed that fundal height was not a risk factor for hypotension after caesarean spinal anesthesia in parturients with scarred uterus.

This was a prospective study on hypotension after caesarean spinal anesthesia. The subjects were parturients with scarred uterus. This is the first study to discuss the risk factors for hypotension after spinal anesthesia when a low dose of local anesthetic was used with sulfentanyl. Moreover, exercise history in gestation was examined for the first time in this study. However, this study had some limitations, such as the time taken to collect data and the failure of including weight gain in the stratification study.

\section{Conclusion}

When low dose of bupivacaine was used with sulfentanyl in parturients with scarred uterus, the incidence of hypotension after spinal anesthesia was $45.96 \%$. The weight gain in gestation, post-pregnancy BMI, exercise history in gestation and the dermatomal level of analgesia were the risk factors for the occurrence of hypotension after caesarean spinal anesthesia in parturients with scarred uterus. The novelty of this study is that it is the first time to incorporate exercise during pregnancy into the study, which has never been before.However, the knowledge of these risk factors should be useful in increasing vigilance in those patients most at risk for hypotension, in allowing for more timely therapeutic intervention, or even in suggesting the use of alternative methods of spinal anesthesia.

\section{Abbreviations}

BPD:biparietal diameter;FL:biparietal diameter;BMl:body mass index; Hb:hemoglobin;Hct:Hematocrit.

\section{Declarations}

\section{Ethics approval and consent to participate}

Ethical approval from China Ethics Committee of Registering Clinical Trials was obtained (ChiECRCT20190086). Written informed consents were obtained from participants before inclusion.

\section{Consent for publication}

Not applicable 
Availability of data and materials

The data that support the findings of this study are available from The First Affiliated Hospital of Wannan Medical College; however, they are not publicly available. Data are however available from the authors upon reasonable request after permission of The First Affiliated Hospital of Wannan Medical College.

\section{Competing interests}

The authors declare that they have no competing interests.

\section{Funding}

The study was financially supported by Wannan Medical College Fund of The First Affiliated Hospital of Wannan Medical College (grant no. KY 86950428).The funder is the first author and corresponding author of this article.

\section{Authors' contributions}

WC was responsible for the conception and design of the study, analysis of the data, and writing the manuscript. YC,YQC shared in data collection. YL,FD shared in assessment and obstetric management of the patients. LG, FD made substantial contribution in the design of the study, writing and revising the manuscript.WC,YC,YQC,YL,FD,BW and LG shared in writing and revising the manuscript. All authors had read, revised and approved the final manuscript.

\section{Acknowledgements}

We would thank Dr. Chenlin Hou, professor of anesthesia, The First Affiliated Hospital of Wannan Medical College. We would thank Dr. Yihui Zhou, professor of Obstetrics and Gynecology Department, The First Affiliated Hospital of Wannan Medical College.

\section{References}

1.Arzola C,Wieczorek PM.Effificacy of low-dose bupivacaine in spinal anaesthesia for caesarean delivery: systematic review and meta-analysis.Br J Anaesth.2011;107:308-18.

2.Roofthooft E,Van de Velde M.Low-dose spinal anaesthesia for caesarean section to prevent spinalinduced hypotension.Curr Opin Anaesthesiol.2008;21:259-62.

3.Chinachoti T,Tritakarn T.Prospective study of hypotension and bradycardia during spinal anesthesia with bupivacaine:incidence and risk factors, part two.J Med Assoc Thai.2007;90:492-501.

4.Nag DS,Samaddar DP,Chatterjee A,Kumar H,Dembla A.Vasopressors in obstetric anesthesia:A current perspective. World J Clin Cases.2015;3:58-64. 
5.Norris MC.Hypotension during spinal anesthesia for caesarean section:Does it affect neonatal outcome?RegAnaesth,1987;12:191-193.

6.Mercier FJ,Augè M,Hoffmann C,Fischer C,Le GA.Maternal hypotension during spinal anesthesia for caesarean delivery.Minerva Anestesiol.2013;79:62-73.

7.Fakherpour A,Ghaem H,Fattahi Z,ZareeS.Maternal and anaesthesiarelated risk factors and incidence of spinal anaesthesiainduced hypotension in elective caesarean section:A multinomial logistic regression.Indian $\mathrm{J}$ Anaesth.2018;62:36-46.

8.Van de Velde M, Van Schoubroeck D, Jani J, et al. Combined spinal epidural anestehsia for Cesarean section: dose dependent effects of hyperbaric bupivacaine on maternal hemodynamics. Anesth Analg.2006; 103:187-190.

9.Farzi F, Mirmansouri A, Naderi Nabi B, et al. Comparing the Effect of Adding Fentanyl, Sufentanil, and Placebo with Intrathecal Bupivacaine on Duration of Analgesia and Complications of Spinal Anesthesia in Patients Undergoing Cesarean Section [J]. Anesth Pain Med.2017;7: e12738.

10.Liang J,Mu Y,Li X,Tang W,Wang Y,Liu Z,Huang X,Scherpbier RW,Guo S,Li M,et al.Relaxation of the one child policy and trends in caesarean section rates and birth outcomes in China between 2012 and 2016: observational study of nearly seven million health facility births.BMJ.2018;360:k817.

11.Canturk M.Effects of isothermic crystalloid coload on maternal hypotension and fetal outcomes during spinal anesthesia for cesarean section:A randomized controlled trial.Taiwan $\mathrm{J}$ Obstet Gynecol.2019;58:428-33.

12.Ohpasanon P,Chinachoti T,Sriswasdi P.Prospective study of hypotension after spinal anesthesia for cesarean section at Siriraj Hospital: incidence and risk factors, Part 2.J Med Assoc Thai.2008;91:675-80.

13.McCulloch WTD, Littlewood DG. Influence of obesity on spinal analgesia with isobaric $0.5 \%$ bupivacaine. Br J Anaesth.1986;58:612-4.

14.Pitkanen MT. Body mass and the spread of spinal anesthesia with bupivacaine. Anesth Analg.1987;66:127-31.

15.Kitahara T, Kuri S, Yoshida J. The spread of drugs used for spinal anesthesia. Anesthesiology.1956;17:205-8.

16.Green NM. Distribution of local anesthetic solutions within the subarachnoid space. Anesth Analg.1985;64:715-30.

17.Ghabach MB, El-Khatib MF, Zreik TG, Matta MS, Mouawad JJ, Karam CJ, et al. Effect of weight gain during pregnancy on heart rate variability and hypotension during caesarean section under spinal 
anaesthesia. Anaesthesia.2011;66:1106-11.

18.Fakherpour A, Ghaem H, Fattahi Z, Zaree S. Maternal and anaesthesiarelated risk factors and incidence of spinal anaesthesia induced hypotension in elective caesarean section: A multinomial logistic regression.Indian $\mathrm{J}$ Anaesth. 2018;62:36-46.

19.Buchheit M 1, Solano R, Millet GP.Heart-rate deflection point and the second heartrate variability threshold during running exercise in trained boys.Pediatr Exerc Sci. 2007;19:192-204.

20.Brenck F, Hartmann B, Katzer C, Obaid R, Brüggmann D, Benson M, Röhrig R, Junger A.Hypotension after spinal anesthesia for cesarean section: identification of risk factors using an anesthesia information management system.J Clin Monit Comput. 2009;23:85-92.

21.Chung SH, Yang HJ, Lee JY, Chung KH, Chun DH, KimBK.The relationship between symphysis fundal height and intravenous ephedrine dose in spinal anesthesia for elective cesarean section.Korean $\mathrm{J}$ Anesthesiol. 2010;59:173-8.

\section{Checklist}




\begin{tabular}{|c|c|c|c|}
\hline Section/Topic & $\begin{array}{c}\text { Item } \\
\text { No }\end{array}$ & Checklist item & $\begin{array}{c}\text { Reported on page } \\
\text { No }\end{array}$ \\
\hline \multicolumn{4}{|c|}{ Title and abstract } \\
\hline & $1 \mathrm{a}$ & Identification as a randomised trial in the title & Page 1 \\
\hline & $1 \mathrm{~b}$ & $\begin{array}{l}\text { Structured summary of trial design, methods, results, and } \\
\text { conclusions (for specific guidance see CONSORT for } \\
\text { abstracts) }\end{array}$ & $\begin{array}{l}\text { Abstract,paragraph } \\
1-4\end{array}$ \\
\hline
\end{tabular}

\section{Introduction}

Background and objectives

2a Scientific background and explanation of rationale

2b Specific objectives or hypotheses
Background, paragraph 1

background, paragraph 1

\section{Methods}

Trial design

3a Description of trial design (such as parallel, factorial) including allocation ratio

3b Important changes to methods after trial commencement

Methods, (such as eligibility criteria), with reasons paragraph 1 N/A

Participants

4a Eligibility criteria for participants

\begin{tabular}{|c|c|c|}
\hline & $4 \mathrm{~b}$ & Settings and locations where the data were collected \\
\hline Interventions & 5 & $\begin{array}{l}\text { The interventions for each group with sufficient details to } \\
\text { allow replication, including how and when they were actually } \\
\text { administered }\end{array}$ \\
\hline \multirow[t]{2}{*}{ Outcomes } & $6 a$ & $\begin{array}{l}\text { Completely defined pre-specified primary and secondary } \\
\text { outcome measures, including how and when they were } \\
\text { assessed }\end{array}$ \\
\hline & $6 b$ & $\begin{array}{l}\text { Any changes to trial outcomes after the trial commenced, } \\
\text { with reasons }\end{array}$ \\
\hline \multirow[t]{2}{*}{ Sample size } & $7 a$ & How sample size was determined \\
\hline & $7 \mathrm{~b}$ & $\begin{array}{l}\text { When applicable, explanation of any interim analyses and } \\
\text { stopping guidelines }\end{array}$ \\
\hline
\end{tabular}

Methods, paragraph 1

Methods, paragraph 1

Methods, paragraph 2

Methods, paragraph 1-2

N/A

$\mathrm{N} / \mathrm{A}$

$\mathrm{N} / \mathrm{A}$

Randomisation:

Sequence

8a Method used to generate the random allocation sequence

generation

8b Type of randomisation; details of any restriction (such as blocking and block size)

Allocation 9

Mechanism used to implement the random allocation concealment sequence (such as sequentially numbered containers), mechanism describing any steps taken to conceal the sequence until interventions were assigned

Implementation

10

Who generated the random allocation sequence, who enrolled participants, and who assigned participants to interventions

Blinding

11a If done, who was blinded after assignment to interventions (for example, participants, care providers, those assessing outcomes) and how

11b If relevant, description of the similarity of interventions

Statistical methods

12a Statistical methods used to compare groups for primary and secondary outcomes

12b Methods for additional analyses, such as subgroup analyses and adjusted analyses

\section{Results}

Participant flow (a diagram is strongly 13a For each group, the numbers of participants who were randomly assigned, received intended treatment, and were
Methods, paragraph 2 Methods, paragraph 2

N/A

Methods, paragraph 2

Methods, paragraph 2

Methods, paragraph 2

Page 6-7

Page 6-7

Page 7-14 
recommended)

\begin{tabular}{|c|c|c|c|}
\hline & $13 \mathrm{~b}$ & $\begin{array}{l}\text { For each group, losses and exclusions after randomisation, } \\
\text { together with reasons }\end{array}$ & $\mathrm{N} / \mathrm{A}$ \\
\hline \multirow[t]{2}{*}{ Recruitment } & $14 \mathrm{a}$ & Dates defining the periods of recruitment and follow-up & $\begin{array}{l}\text { Methods, } \\
\text { paragraph } 1\end{array}$ \\
\hline & $14 \mathrm{~b}$ & Why the trial ended or was stopped & $\mathrm{N} / \mathrm{A}$ \\
\hline Baseline data & 15 & $\begin{array}{l}\text { A table showing baseline demographic and clinical } \\
\text { characteristics for each group }\end{array}$ & Page 7-14 \\
\hline Numbers analysed & 16 & $\begin{array}{l}\text { For each group, number of participants (denominator) } \\
\text { included in each analysis and whether the analysis was by } \\
\text { original assigned groups }\end{array}$ & Page 7-14 \\
\hline \multirow[t]{2}{*}{$\begin{array}{l}\text { Outcomes and } \\
\text { estimation }\end{array}$} & $17 \mathrm{a}$ & $\begin{array}{l}\text { For each primary and secondary outcome, results for each } \\
\text { group, and the estimated effect size and its precision (such } \\
\text { as } 95 \% \text { confidence interval) }\end{array}$ & Page 7-14 \\
\hline & $17 \mathrm{~b}$ & $\begin{array}{l}\text { For binary outcomes, presentation of both absolute and } \\
\text { relative effect sizes is recommended }\end{array}$ & Page 7-14 \\
\hline Ancillary analyses & 18 & $\begin{array}{l}\text { Results of any other analyses performed, including subgroup } \\
\text { analyses and adjusted analyses, distinguishing pre-specified } \\
\text { from exploratory }\end{array}$ & Page 7-14 \\
\hline Harms & 19 & $\begin{array}{l}\text { All important harms or unintended effects in each group (for } \\
\text { specific guidance see CONSORT for harms) }\end{array}$ & Page 7-14 \\
\hline \multicolumn{4}{|l|}{ Discussion } \\
\hline Limitations & 20 & $\begin{array}{l}\text { Trial limitations, addressing sources of potential bias, } \\
\text { imprecision, and, if relevant, multiplicity of analyses }\end{array}$ & $\begin{array}{l}\text { Discussion } \\
\text {,paragraph } 1\end{array}$ \\
\hline Generalisability & 21 & $\begin{array}{l}\text { Generalisability (external validity, applicability) of the trial } \\
\text { findings }\end{array}$ & $\begin{array}{l}\text { Discussion } \\
\text {,paragraph } 1\end{array}$ \\
\hline Interpretation & 22 & $\begin{array}{l}\text { Interpretation consistent with results, balancing benefits } \\
\text { and harms, and considering other relevant evidence }\end{array}$ & $\begin{array}{l}\text { Discussion } \\
\text {,paragraph } 1 \\
\end{array}$ \\
\hline \multicolumn{4}{|l|}{ Other information } \\
\hline Registration & 23 & Registration number and name of trial registry & $\begin{array}{l}\text { Abstract,paragraph } \\
5\end{array}$ \\
\hline Protocol & 24 & Where the full trial protocol can be accessed, if available & $\mathrm{N} / \mathrm{A}$ \\
\hline Funding & 25 & $\begin{array}{l}\text { Sources of funding and other support (such as supply of } \\
\text { drugs), role of funders }\end{array}$ & Page 20 \\
\hline
\end{tabular}

\section{Figures}




\section{2 singleton-pregnancy parturients with scarred}

The data about the basic information of the parturients, the gestation, the fetus and the anesthesia has been recorded

systolic pressure drops below $90 \mathrm{mmHG}$ or decreases by $20 \%$ during the time from the completion of anesthesia until the delivery of infant

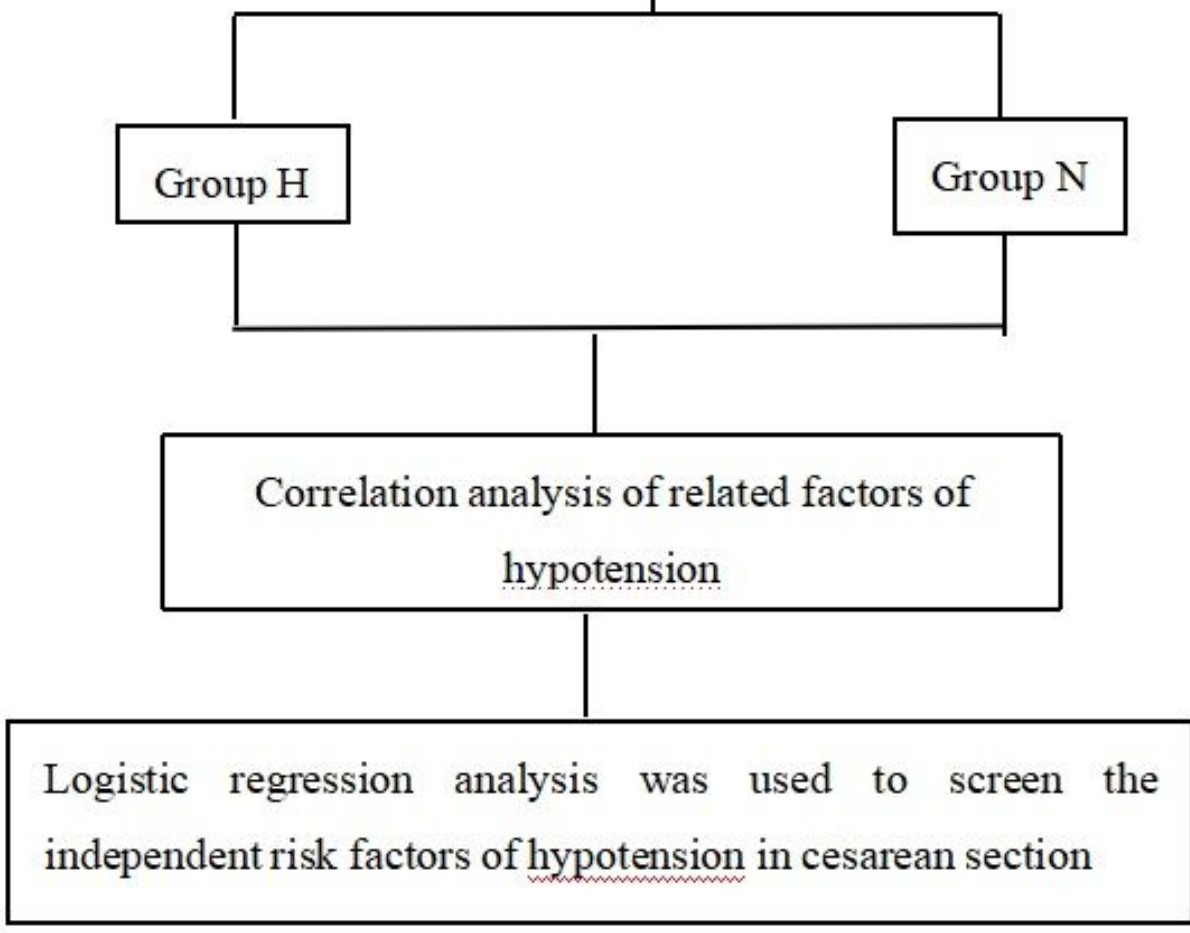

Figure 1

flow chart 